\title{
Correlation between Bound Water and Stability of Anodic Oxide Film on Aluminum
}

\author{
Takumi Haruna*1, Takao Ikeda*2, Masato Miyazaki*3, Akio Nishimoto and Youhei Hirohata \\ Department of Chemistry and Materials Engineering, Faculty of Chemistry, Materials and Bioengineering, \\ Kansai University, Suita 564-8680, Japan
}

\begin{abstract}
It has been investigated that the tiny amount of bound water in anodic oxide film on $\mathrm{Al}$ was quantitatively measured by thermal gas desorption spectroscopy (TDS) and correlation between the amount of bound water in the film and stability of the film was discussed. Al wire specimens were anodically polarized at $20.5 \mathrm{~V}$ in sulfuric acid solution to prepare the anodic oxide film on the specimen. The specimen with the film was then subjected to the film-modification process in which an anodic potential from 1.0 to $2.0 \mathrm{~V}_{\mathrm{Ag} / \mathrm{AgCl}} \mathrm{was}$ applied to the specimen for $180 \mathrm{~s}$ in chloride solution. The specimens for which pitting corrosion did not occur were subjected to the four tests; measurements of thickness of barrier layer in the film, pitting potential, the amount of bound water in the film by the TDS and the amount of water in the porous layer by grow discharge optical emission spectroscopy (GD-OES). As a result, the thickness of the anodic oxide film formed on Al at $20.5 \mathrm{~V}$ was about $25 \mu \mathrm{m}$ and independent of the modification potential. The amount of bound water was quantitatively detected by the TDS, and increased with a rise in the modification potential. However, depth profile of hydrogen, which is considered to correspond to water, in the porous layer of the film detected by the GD-OES was independent of the modification potential. The findings suggested that the bound water is included in the barrier layer. The pitting potential exhibited the maximum value when a modification potential of about $1.5 \mathrm{~V} \mathrm{Ag} / \mathrm{AgCl}$ was applied to the specimen. According to the correlation between the amount of bound water in the film and the pitting potential, the pitting potential rose with an increase in the amount of bound water in smaller amount range, and the amount beyond the small range induces the pitting potential higher. The evidence suggests that control of the amount of bound water is key factor for improving stability of the anodic oxide film on Al. [doi:10.2320/matertrans.L-M2015831]
\end{abstract}

(Received August 6, 2015; Accepted September 1, 2015; Published November 9, 2015)

Keywords: aluminum, anodic oxide film, bound water, barrier layer, sulfuric acid, chloride, modification, thermal gas desorption spectroscopy, grow discharge optical emission spectroscopy

\section{Introduction}

$\mathrm{Al}$ and its alloys have been widely employed in various domestic wares as well as industrial products because of such useful properties as lightness, strength, and corrosion resistance in neutral aqueous solutions in comparison with steels. In addition, anodic oxide film was artificially formed on the material to obtain improvement of the corrosion resistance, hardness, properties for surface design, devices based on the porous structure, and so on. In general, the anodic oxide film of $\mathrm{Al}$ consists of outer porous layer and inter barrier layer. In the viewpoint of further improvement of corrosion resistance, sealing the pore in the film by hot water and coating the different material over the film ${ }^{1,2)}$ have been developed. Since the process, however, cannot leave the unique porous structure of the film, it is desired to seek the process which improve the corrosion resistance of the material remaining the porous structure of the film. In order to do so, it is necessary to control the properties of protective barrier layer of the film.

Stainless steels also exhibit excellent corrosion resistance in neutral aqueous solutions by means of their passive films formed on them. Increasing content of $\mathrm{Cr}$ in the steel is known to induce the improvement of its corrosion resistance, i.e., stability of the passive film. Asami, et al. ${ }^{3)}$ prepared Fe$\mathrm{Cr}$ binary alloys with different $\mathrm{Cr}$ contents, and systematically determined a mass ratio of $\mathrm{Cr}$ cation to both $\mathrm{Cr}$ and $\mathrm{Fe}$ cations in the passive film on the alloys using X-ray

\footnotetext{
${ }^{* 1}$ Corresponding author, E-mail: haruna@kansai-u.ac.jp

${ }^{* 2}$ Graduate Student, Kansai University. Present: JX Nippon Mining \& Metals Corporation, Kouza-gun, Kawagawa 253-0101, Japan

${ }^{* 3}$ Graduate Student, Kansai University
}

photoelectron spectroscopy. As a result, they revealed that slight increase in $\mathrm{Cr}$ content from about 12 mass\% induced significant concentration in $\mathrm{Cr}$ cation in the film, and suggested that the formation of the film containing concentrated $\mathrm{Cr}$ cation resulted in the improvement of corrosion resistance of the steel.

On the other hand, Okamoto and Shibata tried to obtain bound water in the passive film of stainless steel, ${ }^{4,5)}$ pointed out that the bound water played an important role to stability of the passive film, ${ }^{6,7)}$ and then proposed a structural model of the passive film with the bound water. ${ }^{6,7)}$ In this model, the passive film was initially formed as hydrated oxide containing hydroxyl group and/or bound water, and gradually dehydrated into the perfect oxide which exhibited high stability of the film. Since the passive film contains quite tiny amount of bound water, quantitative evaluation of the bound water was difficult. Recently, our research group have tried to characterize the bound water in the passive film on type 304 stainless steel by a different method of a thermal gas desorption spectroscopy (TDS), ${ }^{8,9)}$ and confirmed the similar negative correlation between the amount of bound water and the stability of the passive film.

In addition, our group tried to characterize the bound water in the passive film on $\mathrm{Ti}$ by the $\mathrm{TDS},{ }^{10,11)}$ and revealed positive correlation between the amount of bound water and the stability of the passive film, in opposite manner to that of the stainless steel. Furthermore, the findings suggested that the amount of bound water was key factor to improvement to stability of the passive film as well as that to corrosion resistance of $\mathrm{Ti}$.

According to the findings described above, our group extensively tried to characterize bound water in anodic oxide film on Al formed in sulfuric acid solution by the TDS, and 
confirm the correlation between the amount of bound water and the stability of the passive film.

\section{Experimental Procedure}

Material used in the research was Al (purity: 99.99 mass \%) wire of $1 \mathrm{~mm}$ in diameter. The wire was polished with emery papers (to \#6/0) and cut into about $20 \mathrm{~mm}$ in length. The end of the wire was jointed to stainless steel wire of about $0.8 \mathrm{~mm}$ in diameter and the wire except for $\mathrm{Al}$ part of about $15 \mathrm{~mm}$ in length was covered with shrinkable polytetrafluoroethylene tube. The Al part was immersed into $1.0 \mathrm{kmol} \cdot \mathrm{m}^{-3} \mathrm{NaOH}$ solution at ambient temperature for $30 \mathrm{~s}$ and then rinsed with distilled water.

Anodic oxide film was formed on the $\mathrm{Al}$ wire specimen in $1.0 \mathrm{kmol} \cdot \mathrm{m}^{-3} \mathrm{H}_{2} \mathrm{SO}_{4}$ solution using a two-electrode system. An anodic potential from 18.0 to $23.0 \mathrm{~V}$ against Pt counter electrode was applied to the specimen for $1.8 \mathrm{ks}$ by a power supply unit (KX-100H, Takasago Ltd.). The test solution was kept at 288 or $298 \mathrm{~K}$, and was stagnant or stirred during the film formation.

Since Al with the anodic oxide film suffers pitting corrosion in chloride solution at a potential beyond its pitting potential, it is expected that the film is modified (i.e., degraded without breakdown) in the solution at a potential below the pitting potential, and that the amount of bound water is varied with the modification conditions. Modification of the anodic oxide film on Al was conducted by a threeelectrode system with the specimen electrode, an $\mathrm{Ag} / \mathrm{AgCl}$ $\left(3.3 \mathrm{kmol} \cdot \mathrm{m}^{-3} \mathrm{KCl}\right.$, room temperature) reference electrode and a Pt counter electrode. The specimen with the film was immersed in $1.0 \mathrm{kmol} \cdot \mathrm{m}^{-3} \mathrm{NaCl}$ solution, and then polarized at an anodic potential from 1.0 to $2.0 \mathrm{~V}_{\mathrm{Ag} / \mathrm{AgCl}}$ for $180 \mathrm{~s}$ by a potentiostat (PS-06, Toho Res. Tech.). Some of the specimens suffered pitting corrosion during the modification process. The films of the other specimens which did not suffer pitting corrosion until the period were considered to be successfully modified without break down, and were selected as the specimens for the next four tests; the measurements of thickness of barrier layer for the film, pitting potential of the specimen, the amount of bound water in the film by the TDS and the amount of water in the porous layer of the film by grow discharge optical emission spectroscopy (GDOES).

A thickness of the barrier layer of the anodic oxide film was relatively estimated by the pore-filling technique. ${ }^{12-14)}$ The specimen with the film was immersed in borate buffer solution containing $0.5 \mathrm{kmol} \cdot \mathrm{m}^{-3} \mathrm{H}_{3} \mathrm{BO}_{3}$ and $0.05 \mathrm{kmol} \cdot \mathrm{m}^{-3}$ $\mathrm{Na}_{2} \mathrm{~B}_{4} \mathrm{O}_{7}$. The solution was deaerated with $\mathrm{N}_{2}$ gas and kept at $298 \mathrm{~K}$. A current density of $3.6 \mathrm{~mA} \cdot \mathrm{m}^{-2}$ was applied to the specimen for $60 \mathrm{~s}$ by the power supply unit, and a potential was measured during the test. During the test, a potential rapidly and then gradually rises. An initial increment of the potential $\left(E_{\mathrm{j}}\right)$ is known to correspond to a thickness of the barrier layer of the anodic oxide film. Therefore, the initial increment of the potential was obtained in the way described above.

A pitting corrosion test was conducted in a conventional potentiokinetic method with the three-electrode system as almost same as that introduced in the film-modification process. The three electrodes were connected to the potentiostat, and immersed in a $1.0 \mathrm{kmol} \cdot \mathrm{m}^{-3} \mathrm{NaCl}$ solution deaerated by $\mathrm{N}_{2}$ gas. The solution was kept at $298 \mathrm{~K}$. After achieving stable corrosion potential, the specimen was polarized at a potential of $-0.70 \mathrm{~V}_{\mathrm{Ag} / \mathrm{AgCl}}$ and the potential was scanned in anodic direction at a rate of $0.30 \mathrm{mV} \cdot \mathrm{s}^{-1}$. A pitting potential was determined as the potential at which a current reached $100 \mu \mathrm{A}$.

In the TDS (TDS-200-L Standam, Ulvac Inc.) test, ${ }^{8-11)}$ the specimen was set in the quartz chamber evacuated to about $10^{-7} \mathrm{~Pa}$ for about $54 \mathrm{ks}$ in order to remove the water physically-adsorbing on the film. Thereafter, the specimen was gradually heated up at $5.6 \times 10^{-2} \mathrm{~K} \mathrm{~s}^{-1}$ in the chamber, and then water desorbed out of the film. The desorption rate of water $(m / z=18, m$ : molecular mass, $z$ : charge) was measured by a quadrupole mass spectrometer. A curve of the desorption rate with the specimen temperature during the TDS test is called as a TDS profile.

The GD-OES (GD Profiler2, Horiba Ltd.) was also conducted to the specimen with the film in order to measure the amount of $\mathrm{H}_{2} \mathrm{O}$ in the porous layer of the film. The specimen with the film which was subjected to the modification process was set in the TDS chamber for about $54 \mathrm{ks}$, removed from the chamber into air for a few minutes, and then set to the GD-OES apparatus. After pre-evacuations at about $100 \mathrm{~Pa}$ for various times, measurement of $\mathrm{H}$ by the GD-OES started. The test conditions were as follows; direct current mode, a pressure of $600 \mathrm{~Pa}$ in Ar (purity: 99.9999\%), an electric power of $35 \mathrm{~W}$.

\section{Results and Discussion}

\subsection{Formation of anodic oxide film}

Anodic oxide films were formed on the $\mathrm{Al}$ specimens at several applied potentials. Cross-sections of the specimens with the films formed in the stirred solution at $298 \mathrm{~K}$ were shown in Fig. 1. Potentials of 18.0 and $20.5 \mathrm{~V}$ produced the anodic oxide films of 10.0 and $25.0 \mu \mathrm{m}$ in thickness, respectively. When a potential of $22.0 \mathrm{~V}$ was applied to the specimen, no film was observed on the specimen surface because of dielectric breakdown.

Effect of the film formation potential on a potential increment, $E_{\mathrm{j}}$, which correspond to a thickness of the barrier layer of the film was shown in Fig. 2. It was confirmed that a rise in the film formation potential induced an increase in $E_{\mathrm{j}}$, i.e., an increase in a thickness of barrier layer.

Effect of the film formation potential on a pitting potential, $E_{\text {pit }}$, was shown in Fig. 3. In the case that the solution was stagnant at $298 \mathrm{~K}$, the pitting potential was shifted in high direction with raising the film formation potential above $20.0 \mathrm{~V}$. The pitting potential in the stirred solution at $298 \mathrm{~K}$ was lower than that in the stagnant solution and was independent of the film formation potential to $21.5 \mathrm{~V}$. The difference in pitting potential by the movement of solution was considered to be resulted from the temperature at the specimen surface due to the film formation process. That is, the temperature at the specimen surface in the stagnant solution seems to be higher than that in the stirred solution kept at $298 \mathrm{~K}$. In order to confirm the effect of film formation temperature on the pitting potential, a stirred solution kept 

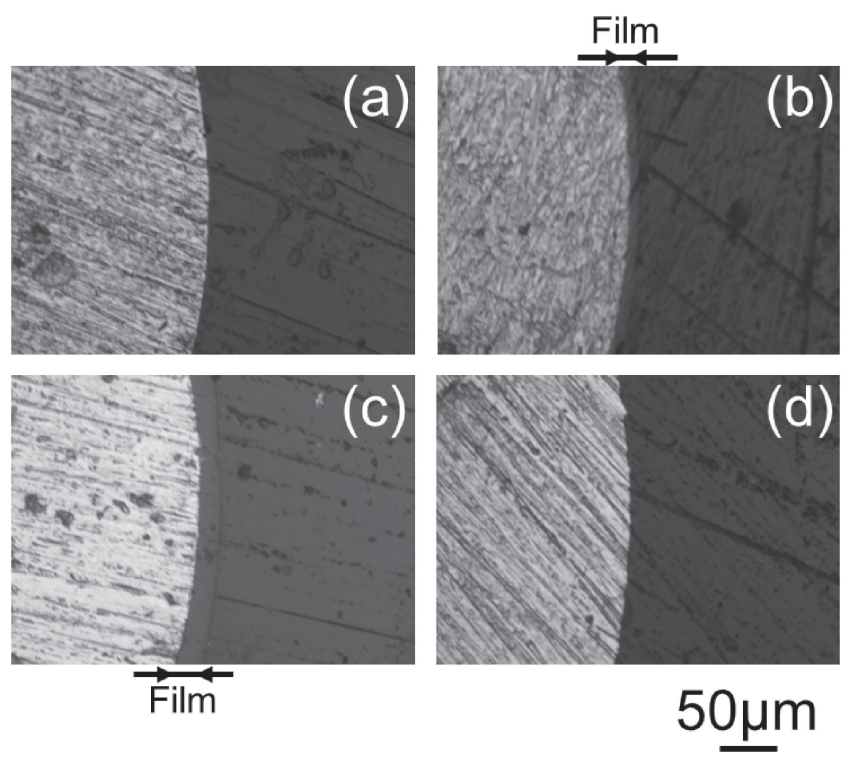

Fig. 1 Cross-sections of the specimens with the films formed in the stirred solution at $298 \mathrm{~K}$. Film-formation potential: (a) without polarization, (b) 18.0 , (c) 20.5 , and (d) $22.0 \mathrm{~V}$.

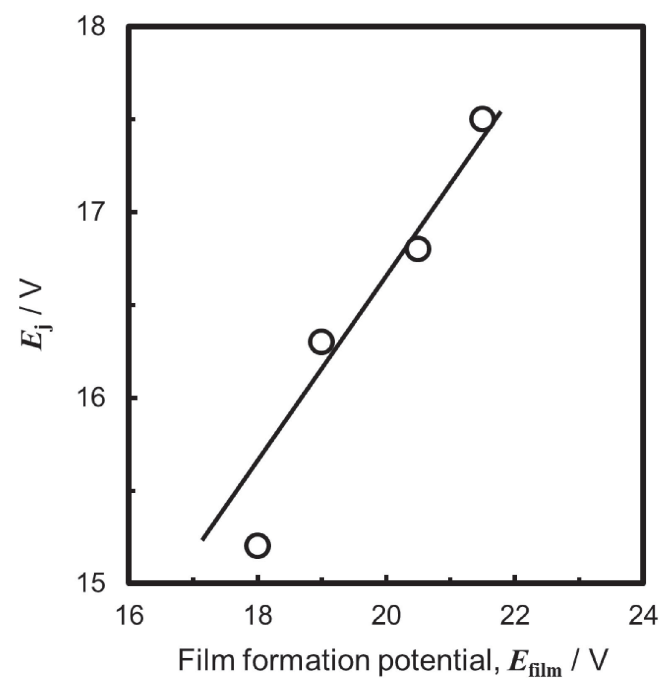

Fig. 2 Effect of the film formation potential on a potential increment, $E_{\mathrm{j}}$, which correspond to a thickness of the barrier layer of the film.

at $288 \mathrm{~K}$ was employed. As a results, pitting potential was almost independent of the film formation potential from 20.0 to $23.0 \mathrm{~V}$, and was slightly lower than that in the stirred solution at $298 \mathrm{~K}$. Therefore, it was confirmed that lower pitting potential was resulted from lower temperature of the film formation solution.

From the results, the film modification test was conducted to the specimens with anodic oxide films formed at $20.5 \mathrm{~V}$ in the solution at $298 \mathrm{~K}$ with and without stirring.

\subsection{Modification of Anodic Oxide Film}

\subsubsection{Thickness of the film}

The anodic oxide film was formed on the specimen at $20.5 \mathrm{~V}$ in the stirred solution, and then the specimen was polarized at a constant potential from 1.0 to $2.0 \mathrm{~V}_{\mathrm{Ag} / \mathrm{AgCl}}$ for $180 \mathrm{~s}$ in the $\mathrm{NaCl}$ solution to modify the film. Cross sections of the specimens with and without the modification process

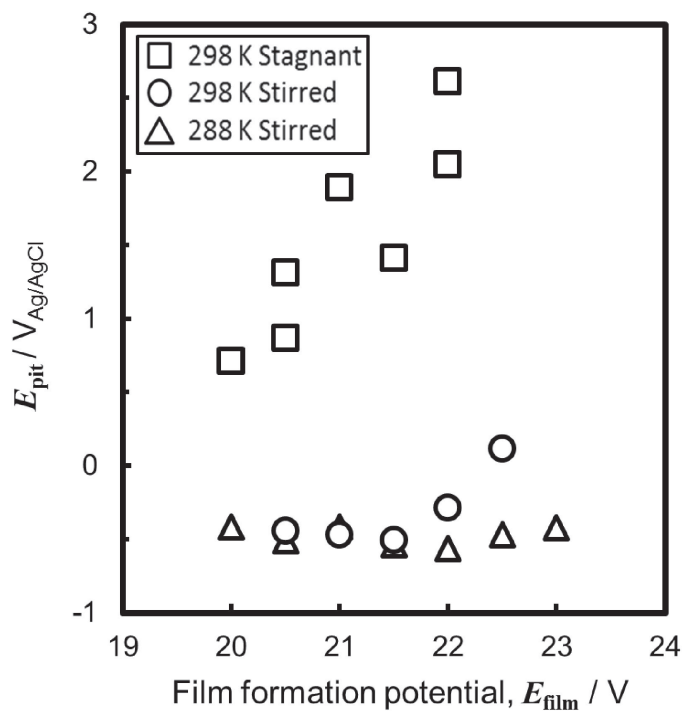

Fig. 3 Effect of the film formation potential on a pitting potential, $E_{\text {pit }}$.
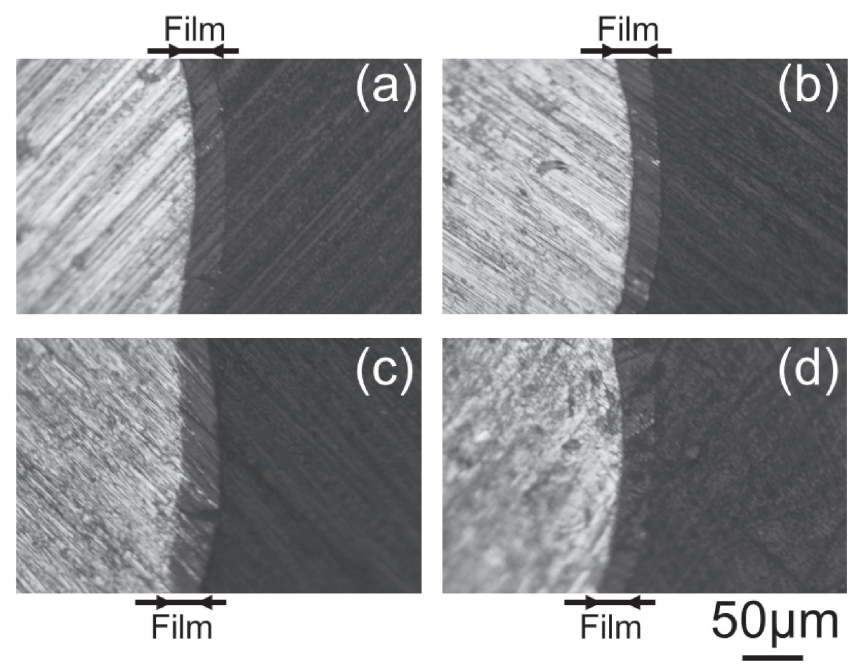

Fig. 4 Cross sections of the specimens with and without the modification process. Film-modification potential: (a) without modification, (b) 1.0, (c) 1.5 , and (d) $2.0 \mathrm{~V}_{\mathrm{Ag} / \mathrm{AgCl}}$.

are shown in Fig. 4. The as-formed film of the specimens had a thickness of about $25 \mu \mathrm{m}$, and the film thickness was almost independent of the film modification potential.

\subsubsection{Thickness of barrier layer in the film}

Effect of the modification potential on a potential increment $\left(E_{\mathrm{j}}\right)$ of the specimen was shown in Fig. 5. In comparison with Fig. 2, the modification potential did not sufficiently affect $E_{\mathrm{j}}$, that is, the thickness of the barrier layer.

\subsubsection{The amount of bound water in the film}

The specimens with the films modified various potentials were subjected to the TDS test. A TDS profile of $\mathrm{H}_{2} \mathrm{O}$ from the specimen with as-formed film is shown in Fig. 6 as a typical example. The desorption rate of $\mathrm{H}_{2} \mathrm{O}$ was quite small at around $300 \mathrm{~K}$ because physically-adsorbed $\mathrm{H}_{2} \mathrm{O}$ was almost removed by setting the specimen with the highly evacuated chamber for about $54 \mathrm{ks}$. As the specimen was heated, the rate steeply increased with a rise in temperature to about $350 \mathrm{~K}$, and then gradually decreased. The rate was integrated with the heating time to obtain the amount of $\mathrm{H}_{2} \mathrm{O}$ 


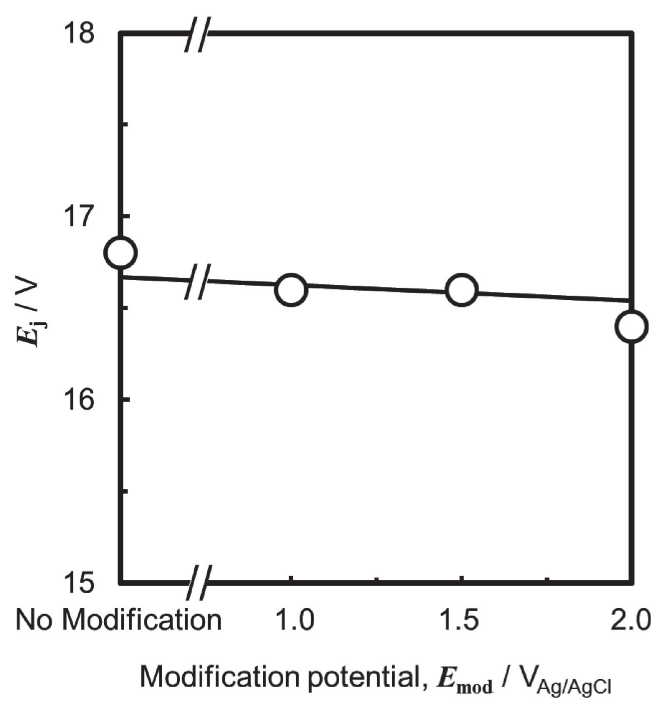

Fig. 5 Effect of the modification potential on a potential increment, $E_{\mathrm{j}}$, of the specimen.

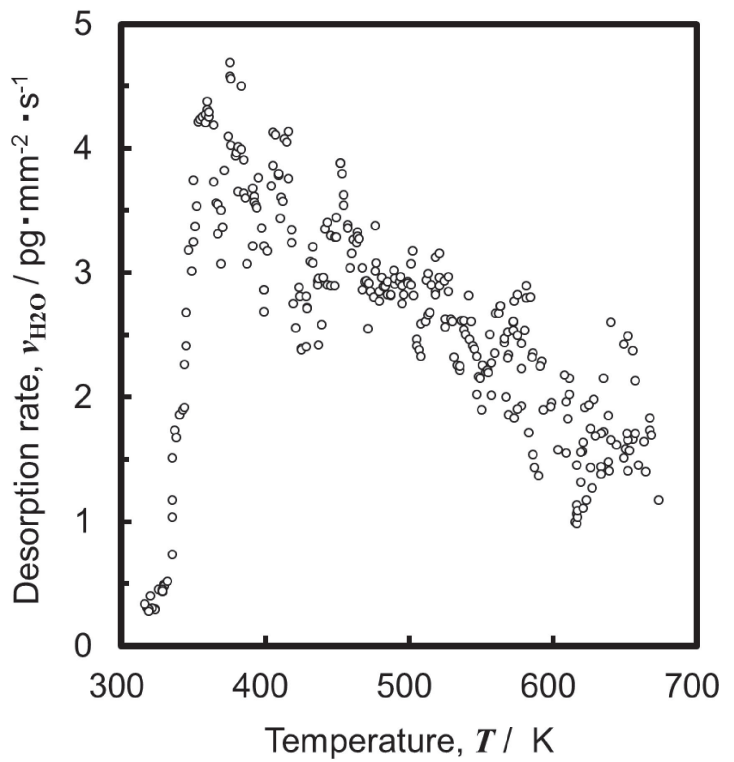

Fig. 6 A typical example of the TDS profile of $\mathrm{H}_{2} \mathrm{O}$ from the specimen with as-formed film.

desorbing from the film. It is noted that the integrated value of the background curve was deducted from the former integration value to obtain an accurate amount of $\mathrm{H}_{2} \mathrm{O}$ in the film.

The amount of $\mathrm{H}_{2} \mathrm{O}$ desorbing from the film was summarized as a function of the modification potential, and shown in Fig. 7. It was obvious that the amount of $\mathrm{H}_{2} \mathrm{O}$ increased with a rise in the modification potential. It is known that $\mathrm{Al}$ with anodic oxide film suffer pitting corrosion in the chloride solution, and that the pitting corrosion more easily occurs when higher potential was applied to the material. Therefore, it is imagined that larger amount of $\mathrm{H}_{2} \mathrm{O}$ in the film induces degradation of the film to initiate pitting corrosion. From the viewpoint, the specimen with modified film was subjected to the pitting corrosion test.

\subsubsection{Pitting potential of the specimen}

The pitting potential of the specimen subjected to film

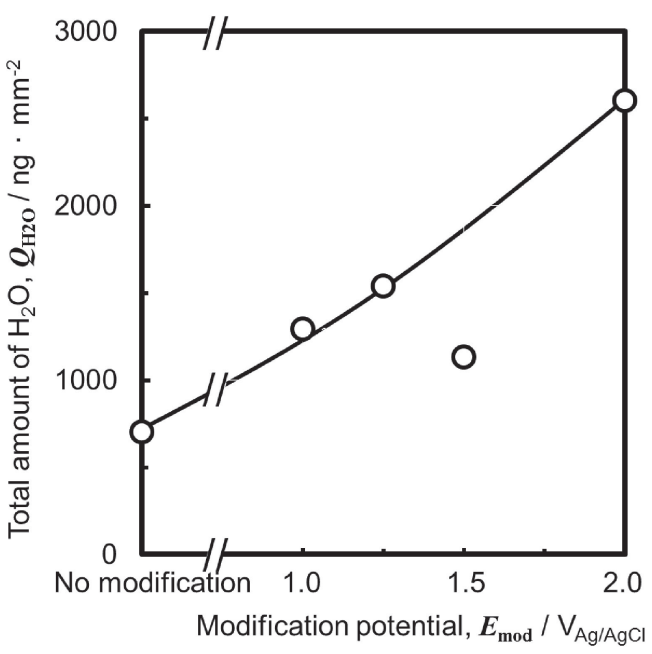

Fig. 7 Effect of the modification potential on the amount of $\mathrm{H}_{2} \mathrm{O}$ desorbing from the film.

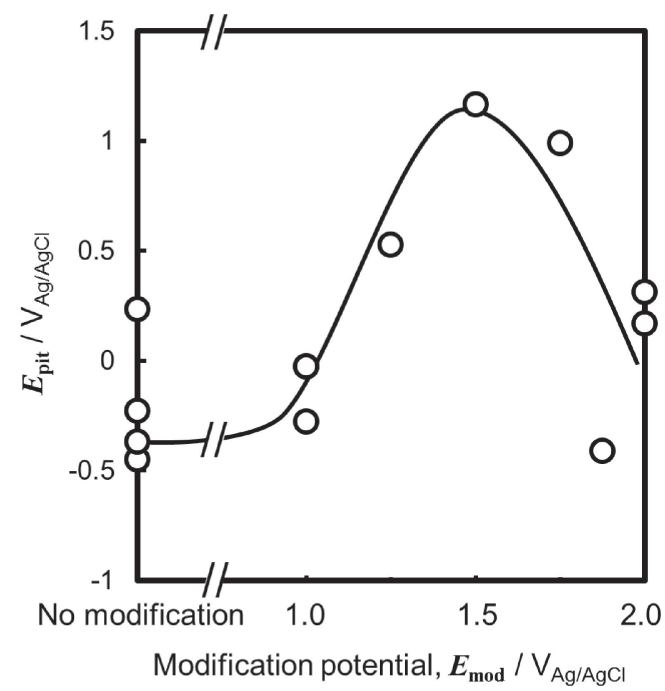

Fig. 8 Effect of the modification potential on the pitting potential of the specimen.

modification process was summarized and shown in Fig. 8. The pitting potential of the specimen without modification was around $-0.3 \mathrm{~V}_{\mathrm{Ag} / \mathrm{AgCl}}$. A rise in the modification potential to about $1.5 \mathrm{~V}$ induced a rise in the pitting potential, and the modification potential beyond $1.5 \mathrm{~V}$ lowered the pitting potential. Therefore, the findings indicate that modification process for the film by applying the potential in the chloride solution does not always degrade the film but improve stability of the film in case.

\subsubsection{Correlation between the amount of bound water and the pitting potential}

Correlation between the amount of $\mathrm{H}_{2} \mathrm{O}$ desorbing from and pitting potential of the specimen under the same modification conditions was shown in Fig. 9. The higher pitting potential was obtained for the specimen with the film containing the larger amount of $\mathrm{H}_{2} \mathrm{O}$ to about $1300 \mathrm{ng} \cdot \mathrm{mm}^{-2}$, and the lower pitting potential was induced by larger amount of $\mathrm{H}_{2} \mathrm{O}$ beyond $1300 \mathrm{ng} \cdot \mathrm{mm}^{-2}$. In other words, it is possible to improve stability of the anodic oxide film by controlling the amount of bound water appropriately. 


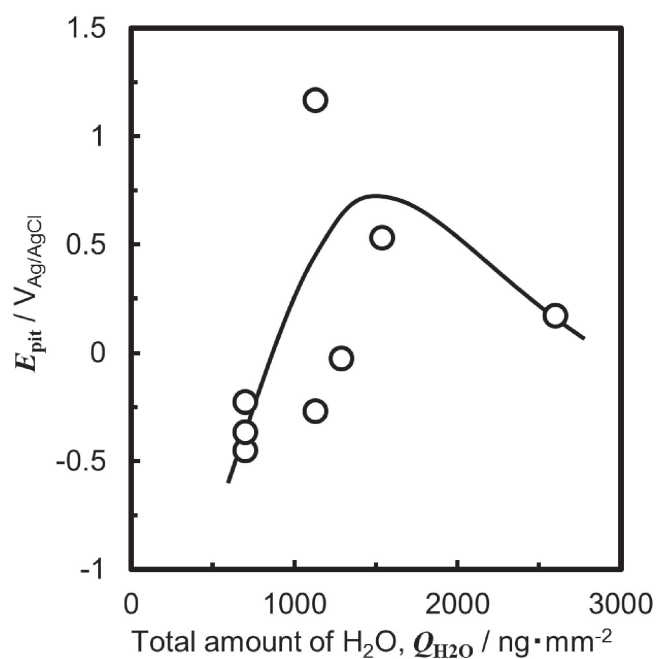

Fig. 9 Correlation between the amount of $\mathrm{H}_{2} \mathrm{O}$ and pitting potential of the specimen with the anodic oxide film formed in the stirred sulfuric acid solution followed by modified in the chloride solution.

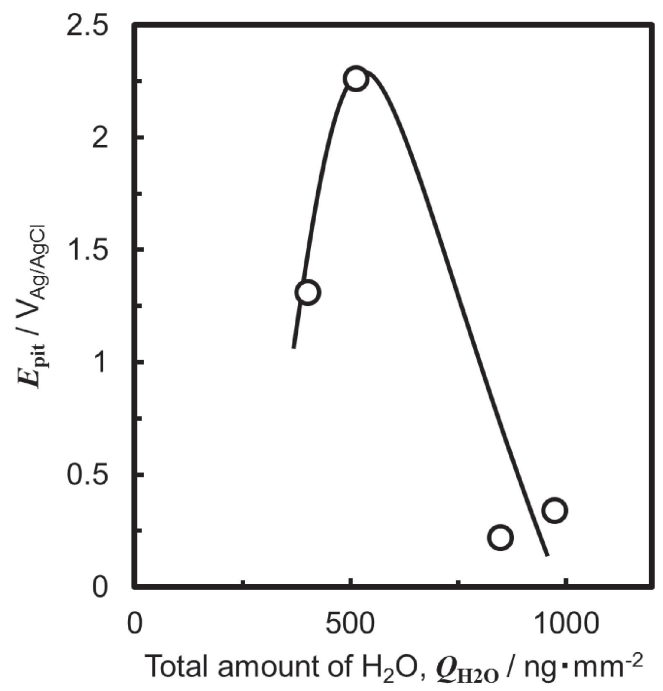

Fig. 10 Correlation between the amount of $\mathrm{H}_{2} \mathrm{O}$ and pitting potential of the specimen with the anodic oxide film formed in the stagnant sulfuric acid solution followed by modified in the chloride solution.

The film was formed on the Al specimen at the same applied potential of $20.5 \mathrm{~V}$ in the stagnant solution of $298 \mathrm{~K}$, and the specimen was subjected to the same modification process as described before. From the specimens, correlation between the amount of $\mathrm{H}_{2} \mathrm{O}$ and pitting potential of the specimen was also summarized in Fig. 10. The amount of $\mathrm{H}_{2} \mathrm{O}$ desorbing from the film formed in the stagnant solution was smaller than that in the stirred solution, and the result is considered to be due to high temperature of the specimen surface by the stagnant solution. While, the maximum pitting potential was obtained at about $500 \mathrm{ng} \cdot \mathrm{mm}^{-2}$ in the measured range of the amount of $\mathrm{H}_{2} \mathrm{O}$, indicating similarity to that of the specimen with the film formed in the stirred solution.

\subsubsection{The amount of water in the porous layer on the} film

The present results indicated the amount of $\mathrm{H}_{2} \mathrm{O}$ was dependent on the modification potential as shown in Fig. 7. Since it is considered that the potential does not affect porous

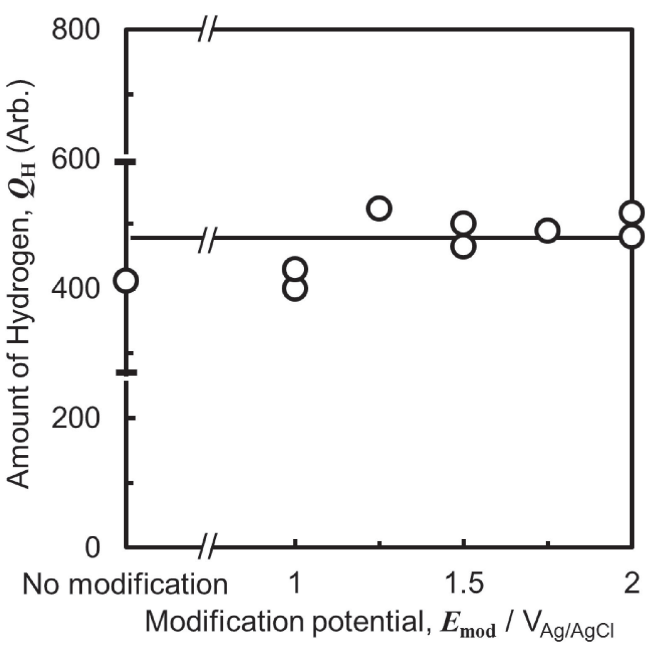

Fig. 11 Effect of modification potential on the amount of $\mathrm{H}$ in the porous layer of the anodic oxide film obtained by the GD-OES.

layer but barrier layer of the anodic oxide film when the potential is applied to the specimen with the film. Therefore, it is guessed that the $\mathrm{H}_{2} \mathrm{O}$ whose amount depends on the modification potential exists in the barrier layer, not in the porous layer. In order to confirm the amount of $\mathrm{H}_{2} \mathrm{O}$ in the porous layer of the modified film, the GD-OES was conducted to the specimen with the modification process. Since the GD-OES cannot detect $\mathrm{H}_{2} \mathrm{O}$ but $\mathrm{H}$, a depth profile of $\mathrm{H}$ for the porous layer of the modified film was obtained. The specimen pre-evacuated in the TDS chamber under about $10^{-7} \mathrm{~Pa}$ for about $54 \mathrm{ks}$ was once exposed in air for a few minutes because of removing the specimen from the TDS chamber and setting it to the GD-ODS apparatus. The asexposed specimen showed the amount of $\mathrm{H}$ in the whole depth profile, especially the amount around the surface area was relatively larger. The detection of $\mathrm{H}$ is considered to be resulted from $\mathrm{H}_{2} \mathrm{O}$ adsorbing on the surface of the porous layer. The specimen was, therefore, kept in a GD-OES chamber evacuated around $100 \mathrm{~Pa}$ for 1.8 and $10.8 \mathrm{ks}$ before the GD-OES test. The pre-evacuation for $1.8 \mathrm{ks}$ sufficiently reduced the amount of $\mathrm{H}$, i.e., removed the adsorbing $\mathrm{H}_{2} \mathrm{O}$, and that for $10.8 \mathrm{ks}$ exhibited almost same reduction of $\mathrm{H}$ as that for $1.8 \mathrm{ks}$. An integration value of $\mathrm{H}$ with the depth for the specimen pre-evacuated for $1.8 \mathrm{ks}$ was calculated as an index of the amount of $\mathrm{H}_{2} \mathrm{O}$ in the porous layer. Effect of modification potential on the amount of $\mathrm{H}$ was shown in Fig. 11. The figure indicated the porous layer of the specimen without modification process included tiny amount of $\mathrm{H}$, i.e., $\mathrm{H}_{2} \mathrm{O}$, and the amount of $\mathrm{H}$ was independent of the modification potential. Since the amount of $\mathrm{H}_{2} \mathrm{O}$ detected by the TDS is dependent on the modification potential, the findings suggest that the modification potential affects the variation of the amount of $\mathrm{H}_{2} \mathrm{O}$ in the barrier layer, not that in the porous layer.

\subsubsection{Contribution of the bound water to the stability of anodic oxide film}

As described in the introduction section, the higher stability of passive films formed on stainless steels was controlled by at least two factors: One is higher concentration of $\mathrm{Cr}$ cation in the film, and the other is lower concentration of hydroxide and/or bound water in the film. In the latter 
case, it has been considered that the stainless steels initially provides the passive film with relatively large amount of hydroxide and bound water, and the film was dehydrated to change into stable oxide. According to the dehydration process, the film was stabilized to the environment containing chloride. The trend of film stability indicates that lower amount of bound water relates with higher stability of the film, i.e., higher pitting potential of the specimen, and the phenomenon for Type 304 stainless steel was confirmed by the same technique in the previous research. ${ }^{4-8)}$

On the other hands, the present research group also investigated previously correlation between the amount of bound water and pitting potential of $\mathrm{Ti}$ passivated at 5.0 $\mathrm{V}_{\mathrm{Ag} / \mathrm{AgCl}}$ in a sulfuric acid solution at $353 \mathrm{~K}$, and revealed that the two parameters of the amount of bound water and the pitting potential was almost independent of film formation time to about $20 \mathrm{ks}$, and progression of the time beyond $20 \mathrm{ks}$ induced larger amount of bound water and higher pitting potential. In addition, the findings provided a positive correlation between the amount of bound water and the pitting potential in contrast. It was reported that titania gel containing a lot of hydroxide and bound water exhibited property of cation-exchange, that is, that of avoiding anion contact. ${ }^{15,16)}$ The property is expected to add the hydrated passive film of Ti to stabilize the film.

Present results on anodic oxide film of Al showed both of the two trends: One was a positive correlation between amount of bound water and pitting potential in the lower amount of bound water, which is similar to the trend of passive film on Ti. The other was a negative correlation between them in the higher one, which is similar to the trend of passive film on stainless steel. The former evidence of $\mathrm{Al}$ may be explained that the surface of barrier layer, bottom of pore, in the anodic oxide film is appropriately hydrates to avoid anions from the barrier layer, and then stabilized to raise the pitting potential. While, the latter one may be explained that the barrier layer is excessively hydrated to change loose structure, and then lower the pitting potential. The reason why application of anodic potential induces hydration of the film is under discussing.

\section{Conclusions}

Al wire specimens with anodic oxide films were subjected to the film modification process in which an anodic potential was applied to the specimen in chloride solution. For the specimens, correlation between the amount of bound water and stability of the film was discussed. The important findings were summarized as follows:

(1) The thickness of the anodic oxide film, about $25 \mu \mathrm{m}$, was independent of the modification potential.

(2) The amount of bound water was quantitatively detected by the TDS, and increased with a rise in the modification potential.

(3) Depth profile of hydrogen, which is considered to correspond to water, in the porous layer of the film detected by the GD-OES was independent of the modification potential. The findings suggested that the bound water is included in the barrier layer.

(4) The pitting potential exhibited the maximum value when a modification potential of about $1.5 \mathrm{~V}_{\mathrm{Ag} / \mathrm{AgCl}}$ was applied to the specimen.

(5) According to the correlation between the amount of bound water in the film and the pitting potential, the pitting potential rose with an increase in the amount of bound water in smaller amount range, and the amount beyond the small range induces the pitting potential higher.

(6) The present results suggest that control of the amount of bound water is key factor for improving stability of the anodic oxide film on $\mathrm{Al}$ as remaining the porous structure.

\section{Acknowledgement}

This research was financially supported by The Light Metal Educational Foundation, Inc.

\section{REFERENCES}

1) S. Hirai, S. Aizawa, K. Shimakage and K. Wada: J. Jpn. Inst. Metals 59 (1995) 547-553 (in Japanese).

2) H. Masuda and N. Baba: J. Surf. Finish. Soc. Jpn. 43 (1992) 150-153 (in Japanese).

3) K. Asami, K. Hashimoto and S. Shimodaira: Corros. Sci. 18 (1978) 151-160.

4) G. Okamoto and T. Shibata: Nature 206 (1965) 1350.

5) G. Okamoto and T. Shibata: Proc. 3rd International Congress on Metallic Corrosion, (MIR Publish., Moscow, 1966) Vol. 1, pp. 396404.

6) G. Okamoto and T. Shibata: Corros. Sci. 10 (1970) 371-378.

7) G. Okamoto: Corros. Sci. 13 (1973) 471-489.

8) T. Haruna, T. Sanuki and Y. Nishiuma: ECS Trans. 16 (2009) 307-312.

9) T. Haruna and M. Hirose: Proc. 18th International Corrosion Congress (Australasian Corrosion Association, Australia, 2011), No. 365 in CDROM.

10) T. Haruna, S. Ito and K. Kimoto: Abstract of 222nd Meetings of The Electrochemical Society (The Electrochemical Society, USA, 2012) No. 2187 in CD-ROM.

11) T. Haruna, S. Ito, K. Kimoto and A. Nishimoto: J. Solid State Electrochem. (2015) in press.

12) A. Dekker and A. Middelhoek: J. Electrochem. Soc. 117 (1970) 440448.

13) H. Takahashi and M. Nagayama: J. Metal Finish. Soc. Jpn. 27 (1976) 338-343 (in Japanese).

14) S. Ono and N. Masuko: J. Jpn. Inst. Light Metals 43 (1993) 447-452 (in Japanese).

15) J. Ragai and S. I. Selim: J. Colloid Inter. Sci. 115 (1987) 139-146.

16) J. P. Bonsack: J. Colloid Inter. Sci. 44 (1973) 430-442. 